\title{
Analysis on the Development Path of Public Library Smart Service Under 5G Technology Environment
}

\author{
Jing Niu, \\ ${ }^{I}$ Zhuhai College of Science and Technology, Zhuhai, Guangdong, China \\ "Corresponding author. Email: 1454962484@qq.com
}

\begin{abstract}
With the rapid development of China's economy and technology, the service mode of public libraries has also undergone earth-shaking changes. New $5 \mathrm{G}$ technology is gradually integrated into people's lives. Through the dissection of the promotion and significance of $5 \mathrm{G}$ technology in public libraries, this article analyzes and solves the current problems and dilemmas of public libraries under $5 \mathrm{G}$ digital management, so as to improve the application of 5G technology in public libraries, realize the sharing of book resources, and better serve the broad masses of people.
\end{abstract}

Keywords: 5G technology, Environment, Public library, Service development.

\section{INTRODUCTION}

In current network age, Internet information technology is widely used in all walks of life. It is a general trend for the public libraries, as the important places for disseminating culture and satisfying the spiritual needs of the masses of the public, to use network interconnection information technology to provide intelligent services. Administrators of public libraries must be aware of the importance of network information technology, and use 5G technology to improve the library's management system. The emergence of 5G technology has updated the service development path of public libraries. Through information technology, it not only reduces the work pressure of library managers, but also effectively improves the service efficiency of public libraries, and better meets the spiritual civilization needs of the broad masses of people. Starting from social practice, the author proposes the basic concepts and basic connotations of $5 \mathrm{G}$ technology on the basis of scholars' research, discusses the role and significance of $5 \mathrm{G}$ technology in promoting public libraries, puts forward the current problems and dilemmas of public libraries under 5G digital management, and discusses the development path and specific practical strategies of public library smart services in the $5 \mathrm{G}$ technology environment.

\section{THE BASIC CONCEPTS AND BASIC CONNOTATIONS OF 5G TECHNOLOGY}

In 2014, with the widespread popularity of smart phones, 4G coverage effectively increased the speed of information dissemination. With the further development of science and technology in China, 5G technology turned out to be a reality, changing the work and lifestyle of the people, filling the fragmented time of the people, and enriching the daily life of the people. 5G technology, as the name suggests, is the fifth generation of mobile communication technology. Compared with 4G, 5G technology has faster transmission speed, more convenient information sharing, higher security, and wider range. The emergence of 5G technology has brought in the distance between people, brought a lot of convenience to the lives of the people, and contributed to the construction of intelligent services for public libraries. 


\section{THE ROLE AND SIGNIFICANCE OF 5G TECHNOLOGY IN PROMOTING PUBLIC LIBRARIES}

\subsection{G Technology Can Promote Cloud Services for Public Smart Libraries}

With the support of 5G technology, public libraries can use network technology to improve service efficiency. Under the traditional library service model, people who want to search for books need to look for books one by one on the shelf according to the book category. In addition, people's access to information is also very restricted by time and place. With $5 \mathrm{G}$ technology, people can search for the public number of public libraries in advance, plus the positioning function of $5 \mathrm{G}$ technology, to accurately find the area where they want to find books. This not only reduces the work pressure of library managers, but also provides great convenience for the daily management of books, shortens the time for people to find books, greatly improves the efficiency of people searching for books, and makes it easier for people to find the books they need. In addition, 5G technology can also use digital management technology to calculate the type of books that the customer likes or are interested in through the book keywords that people have searched in the official account, and make personalized recommendations for people. They can be books of the same type related to the work, or other works of the author of the book, so that people can view and study the books in a unified manner. Through the precise push of $5 \mathrm{G}$ technology, readers are provided with a book list, so that readers can read more books of interest to them, and enhance the appeal of public libraries to the general public.

\subsection{Book Rental Through 5G Technology}

The service mode of traditional libraries is very limited, and the content and resources are far from meeting the requirements of the broad masses of people. The cloud computing service in 5G technology can manage all-round and multi-angle library books, and accurately remember when readers borrowed books and when they should be returned. When there is not much time to return, $5 \mathrm{G}$ technology will send text messages to readers according to the contact information left by the reader when borrowing the book, tell readers in advance that the borrowing is about to expire, and ensure that readers finish reading the book within the specified time limit and return it on time. In addition, when the reader has not read the book completely or cannot return it on time due to personal reasons, the book can be renewed online, saving people the time to go to the library in person.

\subsection{G Technology Can Provide People with an Immersive Reading Experience}

Under the traditional library management service model, people can only read a single boring text, and those interesting pictures also require readers to imagine themselves. In the $5 \mathrm{G}$ digital management service mode, the text in the book can be transformed into vivid and interesting pictures or images through 5G technology. The library should strengthen the network construction to ensure that the library's network is smooth and can cover every corner of the library. At present, many readers will choose a fixed time to read in the library. Through VR technology, readers can have a deeper impression and unusual experience of the book content in a mode of both voice and text. Especially for children, this kind of VR technology can help children connect the text in the book with virtual images. For example, children can wear 3D glasses when reading "Twenty Thousand Leagues Under the Sea". In this way, a variety of fish can be seen on the wall of the library, allowing children to experience the magical underwater world depicted in the book, and even interact with the fish by tapping the screen. If the children want to learn more about a certain fish, they can also click on a certain fish displayed on the screen to establish a real-time connection with the Internet through $5 \mathrm{G}$ technology, and the Baidu Encyclopedia page of that fish will appear, allowing children to have a deeper understanding of fish. It can be seen that under the library service model of 5G technology, it will not only effectively stimulate children's interest in reading, and let children discover the joy of reading and make them like to read books, but also be more conducive to help children develop good reading habits, and bring more interesting reading experience for readers, so that readers no longer rely on pure imagination to restore the scenes in the book, and realize the combination of reading and education.

\subsection{Realizing Cloud Classroom Through $5 G$ Technology}

5G technology accelerates the speed of information sharing. With the support of $5 \mathrm{G}$ technology, public libraries can realize cloud classrooms with unlimited time and location. Public 
libraries can cooperate with live webcast platforms and MOOCs and other platforms taught by famous teachers. When there are activities such as book clubs or knowledge lectures, people can participate and interact in real time through VR through the 5G technology of public libraries. At the same time, the whole process of the reading club will be published on the MOOC platform. Readers can also use the library's ultra-fast transmission speed to save and download MOOC resources, so that readers can get a better reading experience.

\subsection{Realizing Library Intelligent Robot Service Through $5 G$ Technology}

Under the traditional library management service model, it is difficult for librarians to take care of every reader. Especially when the library has a large flow of people, it would be difficult to meet the needs of every reader. And under 5G technology, public libraries can implement intelligent robot services. When readers need help, they can call intelligent robots. By clicking on the screen in the middle of the intelligent robots, intelligent services can be realized. This management model can not only effectively reduce the work pressure of librarians, but also bring better quality services to people.

\section{THE CURRENT PROBLEMS AND DILEMMAS OF PUBLIC LIBRARIES UNDER 5G DIGITAL MANAGEMENT}

\subsection{Poor Basic Equipment}

At present, the scientific and technological awareness of some public libraries in China needs to be further strengthened. In the process of $5 \mathrm{G}$ digital management, the basic equipment of the library is relatively poor. Many facilities have been aging due to disrepair for a long time. This is not only detrimental to the sustainable development of 5G digital management, but also brings many unnecessary hidden safety hazards. There are also some libraries that do not pay enough attention to 5G digital management. Library managers do not realize the necessity and importance of library management digitalization. They are vague about scientific and technological knowledge and have a little understanding of the process and operation of 5G digital management system. This kind of management awareness can no longer meet the management requirements of the current information age, nor can it effectively meet the spiritual needs of the broad masses of people.

\subsection{Backward Management of Books and Archives}

At present, there are still traditional paper archives in some libraries in China. Paper files are not only easy to be damaged over time, but also occupy a lot of space, which is not conducive to the collection, inquiry and organization of book information. Under the management method of paper archives, the accuracy of book data will decrease with the increase of workload, which adds to the work pressure for library managers. The backward management of library books and archives is not conducive to the management and protection of books. In addition, the management of paper archives makes it difficult for staff to remember the placement of books, which brings inconvenience to retrieval.

With the continuous progress of the times and the rapid development of society, the material living conditions of the masses of the people are also improving day by day, and the requirements for spiritual civilization are getting higher and higher. Under such background conditions, more and more people go to the library to borrow books and relax. As the flow of people increases day by day, the digital standard for book information will become higher and higher. In order to keep up with the requirements of library management, it is urgent to update the file management method.

\subsection{The Library Book Database Cannot Be Updated in Time}

The library is a public welfare place, and its purpose is not to make a profit. Therefore, in some libraries in China, there is a problem of low efficiency of the digital system. Due to the lack of good material and financial support, the libraries do not have sufficient funds to upgrade and maintain the book database, making the database unable to keep pace with the times. And the work of revising and perfecting book information cannot be carried out in the first time, which greatly reduces the effectiveness of book management. Meanwhile, the superior value of digital collection management cannot be fully utilized. 


\section{THE DEVELOPMENT PATH AND SPECIFIC PRACTICAL STRATEGIES OF SMART SERVICES IN PUBLIC LIBRARIES UNDER THE 5G TECHNOLOGY ENVIRONMENT}

\subsection{Increasing Investment in 5G Digital Management}

The Chinese government should increase investment in the digital management of libraries, provide strong material and financial support for public libraries, ensure a sound library infrastructure, and allow libraries to have sufficient funds to invest in 5G technology. At the same time, library managers must also change their thinking, attach their importance on the $5 \mathrm{G}$ digital management in the library, continue to learn relevant knowledge about library 5G technology, and establish the idea of "lifelong learning". They also need to ensure that they can operate $5 \mathrm{G}$ digital management software proficiently, and understand the maintenance and update of information systems, so as to maximize the advantages of the libraries' $5 \mathrm{G}$ digitalization.

\subsection{Creating Electronic Book Archives}

In the environment of 5G technology, if people want to better utilize the value and advantages of $5 \mathrm{G}$ technology, if they want to make better use of 5G technology to establish a library book digitization system, if they want to effectively improve the effectiveness and scientificity of library management, it is necessary to establish electronic archives of books and sort and classify books according to their basic information. Due to the wide variety of history and culture in China, it is very important to ensure the accuracy and comprehensiveness of book data information. Electronic archives will be more conducive to retrieval, convenient for staff to perform statistics, and for readers to screen, thus improving the standardization of book information to a large extent.

\subsection{Establishing and Improving the Book Database}

In the era of network interconnection, a complete database and management system is very important. Libraries should establish and improve the book database, continuously optimize the classification system of books, update and maintain the book database in a timely manner, and give full play to the great value of 5G. In today's information society, libraries should strengthen the construction of the Internet to make library staff be able to preserve and maintain books through the Internet, so that staff can clearly control the storage location of books, which can reduce the work pressure of managers.

\section{CONCLUSION}

All in all, in the current era of network interconnection and information technology, in the $5 \mathrm{G}$ technology environment, the importance of library 5G digital management of books is selfevident. Libraries must innovate their work ideas, keep pace with the times, and be aware of the role of 5G technology in promoting public library services. By adopting the above measures, the sharing of book information and improve the service efficiency of public libraries can be realized to provide better services to the general public.

\section{AUTHORS' CONTRIBUTIONS} Niu.

This paper is independently completed by Jing

\section{REFERENCES}

[1] Jiang Yiping, Research on the Development Path of Intelligent Serviceof Public Library under 5G Technology Environment [J]. Journal of Library Science, 2020, 42(4): 1-5. (in Chinese)

[2] Feng Yunchen, Innovation and Development of Public Library Service Model Based on 5G Technology [J]. The Library Journal of Henan, 2020, 40(10): 67-68. (in Chinese)

[3] Zhang Liang, The Development of Public Libraries in the $5 \mathrm{G}$ Era $[\mathrm{J}]$. Wen Yuan, 2020,(1): 825-826. (in Chinese)

[4] Wang Bo, Challenges, Opportunities and Strategies of traditional library in $5 \mathrm{~g}$ Era [J]. Library Research, 2020(1): 29-35. (in Chinese)

[5] Chen Lianfang, Library Users Small Data Collection, Analysis and Application in Big Data Environment [J]. Journal of the National Library of China, 2016(3): 69-74. (in Chinese)

[6] Liu Enze, Luo Bin, Research on the Revolution of Smart Libraries in Colleges and Universities in the $5 \mathrm{G}$ Era [J]. Journal of Library Science, 2020(1): 9-12. (in Chinese) 